\title{
REINVENTAR LA ESCUELA A PARTIR DE LOS TEXTOS DE LOS ACTORES ESCOLARES: MAESTROS Y ESTUDIANTES
}

\section{REINVENTING SCHOOL FROM SCHOOL TEXTS ACTORS: TEACHERS AND STUDENTS}

\author{
Carlos Enrique Mosquera-Mosquera ${ }^{1}$, Ingrid Giovana Rondón-Márquez², Jhon Freddy Tique-Bastos ${ }^{3}$
}

\begin{abstract}
RESUMEN
El presente artículo es producto de los resultados de un proceso de investigación llevados a cabo en la IE Carlos Arturo Duque Ramírez de Puerto Nare. El objetivo consistió en comprender los relatos de algunos docentes, como posibles dispositivos pedagógicos para mejorar la práctica docente. Se tomó como metodología la narrativa. Los principales hallazgos se resumen en que permitió comprender: 1) la confesión del relato del docente como un poderoso instrumento para orientar la práctica pedagógica; 2) develó que el conocimiento del sí mismo del maestro mediante la tematización de sí, para mejorar, es fundamental en el campo disciplinar pedagógico; 3) entender que el estudiante es un texto que está abierto para ser leído por el docente; 4) comprender que los estudiantes no son problemas para la escuela, sólo es que no se han sabido leer.
\end{abstract}

Palabras clave: Confesión de sí, conocimiento de sí, tematización de sí, práctica pedagógica, texto.

\begin{abstract}
This article is the result of a process of research done in the IE Carlos Arturo Duque Ramirez from Puerto Nare. The objective was to understand the stories of some teachers as possible pedagogical devices to improve teaching practice. We have choosen narrative as methodology. The main findings are summarized in enabling comprise: 1) the confession of the story of the teacher as a powerful tool to guide teaching practice; 2) unveiled that knowledge of itself the master himself by theming itself to improve, discipline is essential in the field of education; 3 ) understand that the student is a text that is open to be read by the teacher; 4) understand that the students are not problems for the school, I just have not known how to read.
\end{abstract}

Keywords: Self- confession, self-knowledge, self- theming, pedagogical practice, text.

\footnotetext{
Fecha de recepción: Octubre 22 de 2015 / Fecha de aceptación: Mayo 23 de 2016

Tipología: Artículo de Investigación Científica y Tecnológica

Para citar este artículo: Mosquera, M. C., Rondón, M. I. \& Tique, B. J. (2016). Reinventar la escuela a partir de los textos de los actores escolares: maestros y estudiantes. Praxis. Vol. 12, 21-29
}

\footnotetext{
1. Magister en Educación de la Universidad Santo Tomás, Bogotá. Colombia. Doctorando en Educación de la Universidad Nacional de Rosario, Argentina. Email: carlosfilosofo@hotmail.com

2. Magister en Educación de la Universidad Santo Tomás, Bogotá. Colombia. Doctoranda en Educación de la Universidad Nacional de Rosario, Argentina. Docente de tiempo completo de la Universidad Cooperativa de Colombia. Email: ingridocente@gmail.com

3. Magister en Educación de la Universidad Santo Tomás Bogotá. Colombia. Doctorando en Educación de la Universidad Nacional de Rosario, Argentina. Email: jhonftb@hotmail.com
} 


\section{INTRODUCCIÓN}

$\mathrm{L}$ a escuela es un espacio institucional que está cruzado por textos, las paredes son un texto, los estudiantes son otros, y por supuesto, los docentes son otros textos. Precisamente, estos últimos textos, los profesores, son los que mueven la escritura de estas líneas. La experiencia vivida, narrada y confesada de un maestro se convierte en valioso documento de análisis, porque como dice Ricoeur (1996) toda narración es vivida, lo cual significa que la vida humana tiene una dimensión narrativa. En este sentido, hablar de la narración-confesión del maestro, se convierte en un modelo de reflexión para el propio maestro, dado que le permite abrirse para comprenderse y se abre al mismo tiempo a los demás para que también lo comprendan mediante la lectura que hagan de él, pues para Ricoeur (2000) todo texto está abierto a interpretaciones.

Lo anterior facilitaría las intervenciones pedagógicas al preocuparse por entender e interrogar la textualidad, para este caso, que el maestro comprenda su propio texto mediante la confesión de sí, para mejorar la práctica pedagógica y que también comprenda a los alumnos, y esto se puede hacer porque según Noro (2015) "Ricoeur, distingue dos tipos de actitudes que los lectores puede asumir frente a un texto: comprender y explicar" (p.10). Actitudes que en el plano de la dialéctica facilitan la lectura de los acontecimientos y permiten hallar el sentido que, para este caso, el sentido de las buenas prácticas pedagógicas dentro del microcosmos escolar.

Ahora, cuando un maestro se abre a sí mismo para comprenderse mediante su confesión, este maestro tiene facilidad para entender que todo alumno es uno texto abierto que también puede leerse para orientar la práctica pedagógica. Lectura que llevaría automáticamente a desplegar un conjunto de acciones pedagógicas. Ello implicaría entonces comprender al profesor, no como mero dictador de clases en un grupo de alumnos de una institución y en determinado nivel escolar, sino como aquel exégeta que se interroga asimismo y a los estudiantes diariamente como textos en todos los encuentros. Es esta la visión que se quiere dar a conocer en los siguientes acápites.

\section{Tabla 1.}

\section{Población objeto de estudio y criterios de selección}

\begin{tabular}{|l|}
\hline Número Área Edad Criterios de selección \\
\hline $\begin{array}{l}\text { Matemática } 28 \\
\text { Deseo de participar en la investigación, mayor dificultada académica, dé cuenta sobre la experiencia } \\
\text { vivida en su quehacer pedagógico con los estudiantes, percepciones de los docentes sobre sus prácticas, } \\
\text { percepciones de los docentes sobre la actitud de los estudiantes en la escuela }\end{array}$ \\
\hline $\begin{array}{l}\text { Español } 24 \\
\text { Deseo de participar en la investigación, dé cuenta sobre la experiencia vivida en su quehacer, percepcio- } \\
\text { nes de los docentes sobre sus prácticas, percepciones de los docentes sobre la actitud de los estudiantes } \\
\text { en la escuela }\end{array}$ \\
$\begin{array}{l}2 \text { Inglés } 35 \\
\text { Deseo de participar en la investigación dé cuenta sobre la experiencia vivida en su quehacer pedagógico, } \\
\text { percepciones de los docentes sobre sus prácticas, percepciones de los docentes sobre la actitud de los } \\
\text { estudiantes en la escuela }\end{array}$ \\
$\begin{array}{l}1 \text { Religión } 31 \\
\text { Deseo de participar en la investigación, dé cuenta sobre experiencia pedagógica, percepciones de los do- } \\
\text { centes sobre sus prácticas, percepciones de los docentes sobre la actitud de los estudiantes en la escuela }\end{array}$
\end{tabular}




\section{Continuación Tabla 1.}

\section{Número Área Edad Criterios de selección}

1 Ética 32

Deseo de participar en la investigación, dé cuenta sobre experiencia pedagógica con los estudiantes, percepciones de los docentes sobre sus prácticas, percepciones de los docentes sobre la actitud de los estudiantes en la escuela

1 Informática 28

Deseo de participar en la investigación, dé cuenta sobre experiencia pedagógica con los estudiantes, percepciones de los docentes sobre sus prácticas, percepciones de los docentes sobre la actitud de los estudiantes en la escuela

Fuente. Elaboración propia.

\section{METODOLOGÍA}

Para esta investigación se eligió como metodología la narrativa, dado que permite entender que los seres humanos son contadores de historias por excelencia, se narran a sí mismos a través de las experiencias vividas. Argumento este que encuentra simetría con la noción presentada por Connely y Clandinin, retomado por Bolívar, Domino \& Fernández (2001) cuando afirman que: "La razón principal para el uso de la narrativa en la investigación educativa es que los seres humanos somos órganos contadores de historias, organismos que, individual y socialmente, vivimos vidas relatadas" (p.52).

\section{Unidad de análisis}

Como unidades de análisis, se emplearon (2) categorías: i) Confesión del propio texto: la confesión de sí, conocimiento de sí, tematización de sí y ii) Comprensión del otro como texto que habla: conocimiento del otro, tematización del otro.

\section{Instrumentos de recolección de información}

Para las técnicas de recolección de información, se diseñaron tres (3) instrumentos: Entrevista a profundidad, diario de campo y la colcha de retazos, teniendo en cuenta los objetivos y categorías de análisis propuestos.

\section{Momentos de la investigación}

La investigación se llevó a cabo en tres momentos: Planeación, trabajo de campo, análisis y triangulación. En la planeación se definió toda la propuesta de investigación, objetivos, preguntas y marco teórico, metodología. El trabajo de campo comprendió la aplicación de las técnicas propuestas en dicho proceso. Y en la triangulación interpretó las voces de los docentes en esta investigación.

\section{RESULTADOS Y DISCUSIONES}

En esta parte se confronta la información empírica recolectada con fuentes teóricas. Es preciso aclarar que, para estas líneas solo se exponen algunos fragmentos de la información recolectada. El resto de la información obtenida se encuentran en el informe de investigación "Interpretación de las narrativas maestros en la Institución Educativa Carlos Arturo Duque Ramírez, como posible dispositivo pedagógico para guiar la práctica docente” (2015), en la de la presente institución.

\section{La confesión, el relato}

Empecé mis clases de forma dinámica y noté que todos mis estudiantes reían, porque entre otras cosas suelo comenzar con chistes, o con palabras irónicas o jocosas para romper 
el hielo. Ese día, traté que los estudiantes tomaran algunas notas textuales de lo dicho en clase, pero no había dictado dos párrafos cuando noté que 4 alumnos me hablan meneando las piernas de lado a lado, como si me dijeran: No, cuando giraban hacia un lado, y otra vez, no, cuando giraban al lado opuesto. Eran cuatro chicos que, con los movimientos de sus piernas, me decían varías cosas: 1) no estaban interesados en la clase; 2) no deseaban continuar tomando notas; 3) o sencillamente, la temática del día no correspondía a su expectativa, por tanto, no les interesaba mucho el tema (Entrevista profesor de Ética y Valores).

En otra clase, también noté que varios alumnos me hablaban... Mientras explicaba una clase de Filosofía, deslicé mi mirada y observé a una chica pintándose las uñas y contemplando su belleza frente a un espejo de mano. En otro extremo del salón, un chico más, chateaba. Terminó la clase, y para mayor sorpresa cuando llego a la sala de profesores, me doy cuenta que, unos de los estudiantes que me pidió permiso para ir al baño, un compañero profesor lo observó consumiendo sustancias psicoactivas en el baño para hombres (Entrevista profesor de Ética y Valores).

Estos relatos son suficientes para comprender que, en primer lugar, ya no se está a otrora, donde se concebía el alumno como un receptáculo pasivo, porque, de hecho, la versión neopositivista y si se quiere neotayloriana, llamadas hoy competencias, que objetiva al estudiante, ha cambiado no su molde, pero sí su forma, hasta el punto de permitirle movimiento al alumno, para que sea competente en el mundo de hoy, que tiene caracteres de management. Precisamente, analizando este cambio, Ortiz (2011) afirma que "no existe un modelo pedagógico único, omnipotente, capaz de solucionar todos los problemas de aprendizaje que tienen los estudiantes y que permita agrupar la amplia variedad de tipologías que hayan proliferado en la historia de la educación [...]” (p.124).

Y en segundo lugar, al ubicarnos en el presente, en el ya y ahora, se debe tener presente que, la escuela ha sido además de secularizada su matriz por el Estado moderno desde los albores del siglo XVI, y tal secularización se hace más fuerte en el siglo decimonónico; y que hoy, en la contemporaneidad, la escuela se encuentra profanado por los diferentes fenómenos sociales que la invaden.

Sin duda, el relato anterior no es gratuito, tiene una intencionalidad: Coadyuva a repensar la escuela desde su matriz secularizada y profanada, pues según Noro (2012), al estudiar desde una mirada histórica el nacimiento y constitución de la Escuela, concluye que ésta en la actualidad está profana, porque su matriz de sacralidad, ha sido moldeada por el Estado moderno de acuerdo a sus interés, que la escuela de hoy ya no es la misma de la Edad Media, por lo menos en algunos aspectos accidentales.

En consecuencia, al repensar la escuela desde su estado de profanación, a partir de los sujetos como textos escolares, es relevante desde la pedagogía porque se presenta una concepción del texto como tematización de sí (conocimiento de uno mismo) y tematización del otro (conocimiento del otro). Se podría aquí fusionar los aportes de Foucault (2012) (dispositivos de confesión y conocimiento de sí y la noción de "texto" de Ricoeur (1996) \& Rosas (2014) (la acepción del paciente como texto).

\section{Confesión del propio texto: la confesión de sí, conocimiento de sí, tematización de sí}

Al establecer las categorías de confesión del propio texto como confesión de sí, conocimiento de sí, y tematización de sí, automáticamente remiten al discurso Foucaultiano $(2014,2012)$ sobre los dispositivos de confesión relacionados con el decir veraz de sí mismo, y el perfeccionamiento del sujeto mediante el conocimiento de sí mismo (Foucault, 2012); pero también se debe dar cabida a Ricoeur, cuando introduce la categoría del sujeto-texto, que se puede leer para ser comprendido.

Se trata entonces de proponer la confesión de sí, que emana del texto de sí, en busca del conocimiento de sí, pero bajo la tematización de sí, que también ha sido abordada por Runge 
\& Muñoz (2012), encaminada a mejorar la práctica pedagógica, al cruzar la investigación biográfica-narrativa y la formación pedagógica, tendientes a potencializar el campo disciplinar de la pedagogía, y buscar un acercamiento a la vida escolar mediante la descripción de experiencias y fenómenos particulares de la cotidianidad, que generalmente pasan desapercibidos para la reflexión pedagógica en algunos casos. Y pasan desapercibidos por el estado de profanación en el que se encuentra la escuela, cosa lamentable, porque las experiencias docentes son elementos capitales para buscar la transformación de la práctica pedagógica (Mosquera y Rondón, 2016).

La práctica pedagógica debe cambiar, pero a través de la comprensión de los contextos. Así como han cambiado los caracteres accidentales, mas no los caracteres esenciales de la escuela, la práctica docente puede cambiar partiendo de la confesión de sí, conocimiento de sí y tematización de sí. Precisamente, por el cambio de los caracteres accidentales de la escuela, hoy aparecen nuevos relatos, una nueva comprensión de las prácticas humanas, que forman nuevos paradigmas que atraviesan la escuela y a partir de ahí, se tensionan las prácticas del sujeto pedagógico-docente. Así, la generación del conocimiento y su aplicación innovadora, realizadas por los profesionales, nutren a la docencia de prácticas y conocimientos modernos y actualizados (Ureña y Villalobos, 2011).

Se hace necesario entonces que el maestro se tensione asimismo para mejorar y poder ajustarse al cambio. Pero este cambio no es el que describe Romero \& Romero (2013) en $L a$ educación Marrana, donde presenta la historia amorosa del Estado moderno y su esposa: La familia y la escuela, quienes son las encargadas de vehiculizar y vender el relato del Estado, pero que son traicionadas por él, cuando conoce a la educación Marrana, que educa sin tanta inversión económica, presenta métodos y estrategias educativas inéditas que se pueden emplear sin ir a la escuela (cine, teatro, televisión, redes sociales, etc.) y muchos maestro que se quieren ajustar al cambio, al nuevo relato que trae consigo nuevos métodos educativos y formas de educar de la educación Marrana, se lanzan al vacío sin paracaídas, porque un nuevo discurso de amor educativo los ha subjetivado. Pero pasa algo, cuando estos docentes se dan cuenta que, ese discurso de amor que pretendía cambiar los males de la educación les ha sido infiel, porque los ha engañado, no saben qué hacer y se quedan sumergidos en la melancolía por la incertidumbre, sumergidos en los sueños y no en la vigilia que nos habla (González, 2014) porque el hombre que vive dormido sólo vive de ilusiones, de apariencias y no puede conocer la realidad, como sí la puede conocer el hombre que vive despierto, en vigilia. Para el caso propuesto, el hombre que se deja llevar por la educación Marrana, decide quedarse en sueños nada más, por eso no sabe qué hacer ante los fenómenos educativos, no los sabe leer, o si los lee, se queda en lo que Ortiz (2011) denomina subjetividad subjetiva, que son lecturas-interpretaciones superfluas, vagas, vacías, huecas, que se quedan solo en la especulación de los fenómenos educativos. Y no los sabe leer porque no es capaz de desvelar la realidad que está contenido en textos de todo tipo.

Pero además de los docentes que se dejan influenciar por la educación Marrana, están los que sólo rumean del pasado. Aquellos que no están dispuestos tan fácilmente a dejarse convencer por la retórica de amor que propone la Marrana, y mantienen posiciones fijas añorando y rumiando el pasado no tan instrumentalizado de la educación. Con ellos, también pasa algo similar, se quedan sólo rumiando de forma melancólica el pasado. A esto, es lo que González (2014), desde una postura filosófica que llama la "veneración inútil del pasado”, cuando el sujeto adora y venera tanto el pasado, y se dedica a repetir lo que dijo Platón, Aristóteles, Santo Tomas, o cualquier otro pensador, y no más bien recuerda ese pasado, pero con entonaciones que permiten la relectura de los problemas del presente, para que el pasado permanezca abierto y un presente que le dé cabida a nuevas expectativas.

Igual crítica hace Mosquera (2015), pero desde una perspectiva pedagógica, al censurar la postura de muchos maestros que rumiando sobre el pasado y se quejan de los fenómenos educativos que invaden la escuela y no hace nada para transformar la práctica docente. 
Ninguna de las dos posturas arriba señaladas, los que se dejan llevar por la educación Marrana, y los que se oponen al cambio producto de los afanes de la modernidad -los que rumian el pasado- son las que corresponden a la realidad de la escuela de hoy; por lo tanto, deben ser repensadas para reinventar la escuela. La salida no puede ser la actitud melancólica, como sí lo es, la transformación de la propia práctica a través de la confesión de sí para el conocimiento de sí, que nos propone Foucault (2012), dado que, para este autor, no hay transformación sí, si no existe un conocimiento previo de sí para el sujeto. En este caso, el sujeto pedagógico puede tematizar asimismo para transformarse y con ello, su práctica docente. Este conocimiento de sí, que se da gracias al cuidado de sí, en busca de la perfección de sí (Foucault, 2012) es lo que va a posibilitar la transformación de la práctica disciplinar.

Para aceptar tal afirmación, se debe entender que Foucault rastrea el conocimiento de sí en su libro hermenéutica del sujeto en tres momentos: 1) desde Sócrates y Platón; 2) desde la Filosofía Helenística (Seneca, Epicúreo y estoicos); y 3) Medioevo. Respecto al primer momento, en la expresión "conócete a ti mismo" defendido por la ética socrática, que conduce al "ocúpate de ti mismo” épiméleia haute, como una manera de deslizar la mirada sobre sí. Es un estar vigilante para saber guiar el comportamiento, la conducta, el pensamiento para formar el ethos de sí mismo, que permite al ciudadano gobernarse a sí mismo para poder gobernar a los demás; pues, quien no se gobierne a sí mismo, tampoco podrá gobernar a otros. Platón propone algo similar en el sentido de que la razón o alma intelectiva debe gobernar el alma irascible y concupiscible, y de esta manera, el hombre no se pierda en el deseo y apetitos. Esto implica que el alma racional, debe estar buscando su purificación de manera constante a través de la reminiscencia para ocuparse de sí mismo y de esta manera estar lúcida para gobernar.
Nótese que ni en Platón ni Sócrates, ocuparse de sí es encerrase en su mismidad, en el Yo; por el contrario, el ocuparse de sí, es para saberse dirigir, y desde ahí, dirigir y servir sabiamente a la polis-ciudad. Ahora desde una óptica educativa, se puede inferir que el buen maestro es aquel que se ocupa de sí mismo para poder ocuparse de los alumnos, y esto se puede dar a través de la confesión de sí, para el conocimiento de sí, mediante la tematización de sí, para mejorar.

En segundo lugar, en todas las escuelas helenas, se observa una preocupación por el perfeccionamiento constante de sí. Los epicúreos se confesaban constantemente ante sus miembros con la finalidad de buscar la pureza. Los estoicos, de igual manera, se preocupaban tanto de sí que se desconectaban del mundo superfluo, para concentrarse en descubrir los principios y virtudes mediante la ataraxia, en busca de la perfección de su paz interior y ser libres. Por ejemplo, Seneca se preocupaba tanto por los actos correctos que debía realizar en el día, que en la noche hacia un inventario de las acciones realizadas, para detectar dónde había fallado.

En el tercero, se observa cómo en la práctica monacal, el monje vivía una vida ascética y cenobítica, regidos por los dispositivos de confesión permanente, siempre en busca de la verdad y el conocimiento de lo sagrado, para buscar su perfección. Pero resulta que la vida monacal sobre todo en los siglos IV y V, sostiene Foucault (2012), requería de un guía espiritual ya maduro -el maestro- que tenía un dominio y soberanía sobre sí mimo y por tanto podía guiar al discípulo a la perfección; pero este maestro debía de estar lo suficientemente preparado para poder guiar y orientar. Extrapolando esto al tema que se expone, una de las posibles maneras que tiene el maestro de buscar su perfección y preparación, puede ser la tematización de sí. 
Como se puede otear, la noción de épiméleia haute (preocupación por el conocimiento de sí, introspección para buscar la perfección) ha atravesado la historia y practicada de diferentes maneras. Y hoy, ante la caída de relatos que marcaban las notas de identidad de la escuela y los advenimientos de nuevos contra-relatos que la desacralizan, y a veces desactivan al maestro, y no sabe qué hacer porque la perplejidad lo invade, es urgente que el maestro retome la épiméleia haute griega, pero aplicada a los caracteres de la contemporaneidad. Es decir, se necesita que el maestro se ocupe de sí mismo, y devuelva la mirada crítica sobre su práctica. Luego entonces, examinada su práctica mediante el deslizamiento crítico de su mirada, pueda tematizarla para mejorarla. Por lo tanto, el docente debe confesarse a sí mismo como texto permanente; es como imitar a Seneca, revisar lo actuado para buscar el punto que genera la falla.

Obviamente esto tiene un precio que pagar por el movimiento constate del maestro sobre sí. Toda cualificación, perfección tiene un precio que pagar. Foucault (2014-12), explica el precio que tiene el decir veraz sobre sí mismo, pero que es necesario para buscar la perfección y la salvación del hombre creyente. Esto, dentro de un contexto cristiano, al estudiar los dispositivos de confesión en la Edad Media. De igual modo, Foucault (2012) explica en la Hermenéutica del sujeto, cuando analiza los estilos de vida de los estoicos y epicúreos en la Filosofía Clásica y la forma de vida ascética de los monjes y religiosos en el Medioevo. Es decir, en estos estilos de vida se debían pagar un precio para buscar la perfección de sí.

El precio que debe pagar el docente contemporáneo cuando confiesa su texto de sí, obviamente que no hace referencia a la vida de ataraxia $y$ ascética, sino un precio en inversión de tiempo, de sacrificio, y si se permite la expresión, hasta de mortificación-preocupación, para mejorar lo que haya que mejorar de su práctica. De este modo, los escolares y las personas cercanas a ellos se beneficiarían porque la épiméleia haute, como ya se dijo, no se reduce a la individualidad, a buscar la perfección de sí, sin un compromiso con la otredad, la colectividad.

\section{Comprensión del otro como texto que habla: conocimiento del otro, tematización del otro}

Si cada estudiante es un texto, el maestro es un lector que mediante su praxis pedagógica tratará de comprender los textos que se le abren para que ser leídos en la escuela (risas, movimientos corporales, expresiones faciales, inquietudes, la misma habla. etc.), porque

[...] todo lo que es susceptible de ser comprendido puede ser considerado texto: no solamente los escritos mismos, claro está, sino también la acción humana y la historia, tanto individual como colectiva, que solo son inteligibles en la medida en que puedan leerse como textos. (Grondin retomado por Rosas, 2014, p.236)

Pero además toda hermenéutica del sujeto según Alzate, retomado por Rosas (2014), "tiene la intención de comprender el ser a partir de las acciones expresadas en su existencia, intentando recuperar a la vez, el valor óntico de la persona en su actitud propiamente existencial” (p.235). Aquí hay un efecto colateral, la preocupación por el texto del otro abre los ojos para la cualificación del propio texto; es un cuidado de sí, para cuidar a los demás. Porque pareciera que el valor óntico de los textos que se cruzan en el ámbito escolar, se diluyera a veces ante la vida azarosa de la escuela.

En consecuencia, ya no es bien vista la postura de quienes piensan que tal chico o chica es un problema porque se mueve, muestra apatía a veces en clase, se duerme, habla y pregunta. ¡Solo es un texto que se está abriendo para que sea leído! Pero, además, si se concibiera un problema en sentido filosófico, ¡es magnífico!, porque permite al 
maestro tomar la aptitud de filósofo e ir a su encuentro para asentar su mirada sobre él y comprenderlo. Porque el problema, del griego próblema (dificultad que sale al encuentro), consiste en que el esfuerzo que haga el filósofo no es para acallarlo, sino más bien acudir a su llamado, ir a su encuentro problemático, porque si hay perplejidad e incertidumbre hay movilidad de pensamiento (González, 2014). En este caso, también hay movilidad de estrategias pedagógicas, lo que requiere de una aptitud que lo mueva a comprender lo que dicen los textos diariamente. Es necesario entonces, tener una mirada del texto como lo tiene Rosas (2014) de la bioética cuando afirma:

[...] la bioética tiene que centrarse en la persona humana y no perder su mirada sobre ella; tiene que aprender a ver al paciente como un libro abierto que le ofrece múltiples páginas que tienen que ser leídas para dar un dictamen sobre su condición, sobre su salud (p.236).

Esto es clave, lo ontológico del texto debe estar por encima de los aspectos cosméticos de la escuela, porque pareciera que la imagen está sobre todo. Un ejemplo de ello en Colombia es tratar de quedar bien ante las pruebas censales que mide el conocimiento adquiridos a parir de unos estándares nacionales prescriptos, callando el texto que habla, porque no se les escucha, por tanto, no son comprendidos para ser tematizados, y desde ahí orientarlos, guiarlos, venderles un relato sobre el sentido del mundo y la vida.

Y es que no se debe olvidar que los relatos ayudan a vender, a motivar a los textos que escuchan las clases-estudiantes. Ya Noro (2012) señala que una característica de la crisis en la escuela hoy, es la caída de muchos de sus relatos de la modernidad. Luego entonces, si hay caídas de relatos fuertes, el maestro debe instituir otros. No es fácil, pero es un camino para reinventar la escuela, así sea bajo categoría teóricas. He aquí un elemento más dentro del propósito propuesto inicialmente: La confesión de sí, que emana del texto de sí, en busca el conocimiento de sí, pero bajo la tematización de sí; y de esta forma, buscar la transformación de la práctica pedagógica. Es decir, incorporar a la transformación de la práctica pedagógica, la urgencia de nuevos relatos, porque según Noro (2015) son ellos los que poner en funcionamiento los proyectos, generan convicciones, instalan motivaciones, convencen y acompañan los procesos.

\section{CONCLUSIÓN}

La escuela debe ser reinventada desde nuevas experiencias, desde nuevas narrativas. La categoría del maestro como texto, la confesión de sí, para el conocimiento de sí, y de esta manera propiciar la tematización de sí, así como la visión del estudiante, no como problema, sino como texto que desea ser comprendido, es fundamental para la pedagogía, porque es repensar la práctica docente, y la misma escuela. Es pensar en otros moldes para la escuela más allá de las fronteras de la educación homogenizante, burocrática y tecnocrática.

\section{REFERENCIAS BIBLIOGRÁFICAS}

Bolívar, A., Domino, J., \& Fernández, M. (2001 La investigación bibliográfica-narrativa en educación. Enfoque y metodología, Madrid: La Muralla, S.A.

Foucault, M. (2014). Obrar mal, decir la verdad: función de la confesión de la Justicia. Curso de Lovain, 1981: Argentina: Siglo veintiuno Editores Argentina S.A

Foucault, M. (2012). Hermenéutica del sujeto, Argentina: Altamira, p. 39 González, J. (2014) ¿Qué es la Filosofía? La potencia de una pregunta imposible; Buenos Aires, Argentina: Biblos.

Mosquera, C. E. (2015). Rumiar sobre el positivismo o trasformar la práctica educativapedagógica docente. Actualidades Pedagógicas, (65), 217-228.Recuperadohttp:// revistas.lasalle.edu.co/index.php/ap/article/ viewFile/2912/2771

Mosquera, C.E y Rondón, I. (2016). Repensar la escuela: mi confesión, un texto, los estudiantesotros textos. Revista EDUCARE. Vol 19, N3. Barquisimeto

Noro, J. E. (2012), La matriz de la escuela moderna: iescuela sagrada o escuela profana? 
Configuración, crisis y perspectivas. Tomo I: orígenes modernos. Tomo II: Evolución, categorías y propuestas. Editorial Académica Española.

Noro, J. E. (2015). Sistema educativo y universidad, interrogantes y debates iniciales. (Seminario junio de 2012). Rosario, Argentina.

Ortiz, A. (2011). Hacia una nueva clasificación de los modelos pedagógicos: el pensamiento configuracional como paradigma científico y educativo del siglo XXI. Revista Praxis. $\mathrm{N}^{\circ} 10$. p.121 - 17. Recuperado de http://revistas.unimagdalena.edu.co/index.php/praxis/article/ view/18

Romero, J. \& Romero, P. (2013), La Marrana. Infidelidad, celos y melancolía. Un novela de la educación. Homo sapiens. Rosario

Rosas, C. A (2014). El paciente como "texto" según Ricoeur: implicaciones en bioética. Revista
Bioética, vol. 22, núm. 2, 2014, pp. 234-240. Recuperado de http://www.scielo.br/pdf/ bioet/v22n2/05.pdf

Ricoeur, P. (2000). Narratividad, fenomenología y hermenéutica. En. Ranzueque G. A. (ed.) Horizontes del relato. Lecturas y conversaciones con Paul Ricoeur. Universidad Autónoma de Madrid.

Ricoeur, P. (1996). Sí mismo como otro: Siglo XXI. México

Runge, A. K. \& Muñoz, D. A (2012). Los docentes y la tematización de sí: Formación y narración de sí en clave antropocrítica. Medellín: Universidad de Antioquia.

Ureña, Y y Villalobos, W. (2011). La gestión del Conocimiento en instituciones universitarias tecnológicas. Práxis. N 7, p. 155-180. Recuperado de http://revistas.unimagdalena. edu.co/index.php/praxis/article/view/20 